\title{
Effectiveness of early switch from intravenous to oral antibiotics in severe pneumonia
}

\author{
Sharma D', Gaur $\mathbf{A}^{2}$ \\ ${ }^{1}$ Dr. Deepshikha Sharma, Pediatrics, MP State Medical Council; Consultant Pediatrics, Shalby Hospitals, Indore (MP), \\ ${ }^{2}$ Dr. Ajay Gaur, Associate Professor, Head of Department, Pediatrics, Gajra Raja Medical College, Gwalior, MP, India.
}

Address for correspondence: Dr. Deepshikha Sharma, Email: Deepshikha.Sharma@shalby.org

\begin{abstract}
Objectives: Globally, pneumonia is the leading cause of childhood morbidity and mortality. The W.H.O. in its guidelines for the management of severe pneumonia advised that these cases be referred to hospital for inpatient management with parenteral antibiotics. This study was conducted to compare the effectiveness of early switch from intravenous to oral antibiotics in severe pneumonia; and the average duration of stay of children in hospital in both the groups. Setting: Tertiary care hospital. Study design: prospective and observational. Participants: Children classified as severe pneumonia aged 2 to 60 months. Intervention: Children were randomly divided into two groups, Group I: received intravenous antibiotic (ampicillin) at the dose of $200 \mathrm{mg} / \mathrm{Kg} / \mathrm{day} / 6$ hourly. Group II: switched to oral amoxycillin at the dose of $40 \mathrm{mg} / \mathrm{Kg} /$ day/ 8 hourly, after two days of intravenous treatment with ampicillin with same dose as in Group I. General supportive care was provided when indicated. Children were monitored and evaluated for the response to the therapy. Results and Conclusion: There was a similar rate of improvement in the signs of respiratory distress in the two groups and difference in the treatment outcome of the two groups was not statistically significant. The duration of stay in hospital of children in whom intervention with switch on to oral antibiotics was made was significantly reduced. There was reduction in the rate of complications such as oedema/ extravasation, inflammation, abscess at site of cannula in the children in whom switch on to oral antibiotics was made.
\end{abstract}

Key words: Duration, Early, Pneumonia, Severe, Stay

\section{Introduction}

Over the past decade and a half since 2000, significant gains have been made in the reduction of pneumonia and diarrhea mortality in children worldwide. Six conditions account for about $70 \%$ of all child deaths: acute lower respiratory infections, mostly pneumonia $(19 \%)$, diarrhoea (18\%), malaria (8\%), measles, $(4 \%)$, HIV/AIDS (3\%), and neonatal conditions, mainly preterm birth, birth asphyxia, and infections (37\%) [1]. Between 2000 and 2013, the global health community succeeded in decreasing the number of deaths due to pneumonia and diarrhea in children under the age of five years by $44 \%$ and $54 \%$, respectively [2]. However, reductions in annual child mortality rates for pneumonia and diarrhea, the leading killers of children under five, have continued to be only modest. According to the latest child mortality estimates (published in 2014 for

Manuscript received: $4^{\text {th }}$ May 2016

Reviewed: $16^{\text {th }}$ May 2016

Author Corrected; $27^{\text {th }}$ May 2016

Accepted for Publication: $17^{\text {th }}$ June 2016 the year 2013), pneumonia and diarrhea caused over 1.5 million under-five child deaths, respectively accounting for $15 \%$ and $9 \%$ of the 6.3 million under-five deaths that occurred globally in 2013, compared to 1.6 million deaths in 2012 [2]. This means that every 20 seconds, a mother and father lose their young child to one of this deadly, but preventable disease.

As in previous years, the burden of child pneumonia and diarrhea mortality continues to be most heavily concentrated in just a few countries. The 15 countries (India, Nigeria, Pakistan, the Democratic Republic of the Congo, Ethiopia, Angola, China, Afghanistan, Indonesia, Kenya, Sudan, Bangladesh, Niger, Chad, and Uganda) with the greatest number of under-five child deaths from pneumonia and diarrhea in 2013 bore $71 \%$ of the global burden of child deaths from these two diseases in spite of accounting for only $56 \%$ of the world's under five year population [3]. 
The Pneumonia and Diarrhea Progress Report evaluates the progress of these 15 highest-burden countries in implementing high-impact interventions outlined in the Global Action Plan for the Prevention and Control of Pneumonia and Diarrhea (GAPPD) relative to GAPPD coverage targets, where data are available.

The coverage targets for indicators included in this report are $90 \%$ for vaccinations; $90 \%$ for access to pneumonia and diarrhea treatments, which include treatment by a health care provider, antibiotics, oral rehydration salts (ORS), and zinc supplements; and $50 \%$ for exclusive breastfeeding during a child's first six months of life. [4] Childhood respiratory infections have an important impact on society and are a frequent cause of physician visits, consumption of antibiotics and over-the-counter drugs, work loss, and reduction of quality of life [5]. In addition to million deaths, pneumonia causes severe financial difficulties and emotional burden for families and communities. When patients are first admitted to hospital antibiotics are usually given intravenously to provide optimal concentrations in tissue. The duration of intravenous treatment is an important determinant of length of hospital stay. Conventionally, intravenous treatment is continued until definite clinical cure. A switch to treatment with oral antibiotics may allow early discharge and reduce drug costs; but may increase the rate of treatment failure, readmissison and death; it may also increase the workload or family members or health care professionals outside the hospital.

This study was conducted to evaluate the effectiveness of early switch from intravenous to oral antibiotics compared with seven day intravenous treatment regimen in patients with severe community acquired pneumonia.

\section{Objectives}

1. To compare the effectiveness of early switch from intravenous to oral antibiotics in severe pneumonia.

2. To determine the average duration of stay of children in hospital.

\section{Material and Methods}

This prospective and observational study was hospital based and conducted in the department of pediatrics at Kamla Raja Hospital, Gajra Raja Medical College, Gwalior from August'08 to September'09 with due approval from the ethical committee. Patients aged 2 - 59 months fulfilling WHO criteria for severe pneumonia and having no exclusion criteria were taken and randomly divided into two groups; their history, sociodemographic profile, anthropometry and management done was entered in a predesigned proforma. The sample size was calculated as per the formula $4 \mathrm{pq} / \mathrm{l}^{2}$, taking a standard error of $5 \%$, and was estimated as 40 .

WHO classification [6] of acute respiratory tract infection in children presenting with cough, difficult breathing, or both

\begin{tabular}{|c|c|c|}
\hline Classification & Clinical Features & Treatment \\
\hline No pneumonia & no fast breathing; no chest indrawing & No antibiotics \\
\hline Pneumonia & $\begin{array}{c}\text { fast breathing; respiratory rate per minute }>50 \text { breaths } \\
\text { (2- } 11 \text { months of age) or }>40 \text { breaths (12- 59 months of age); } \\
\text { no chest indrawing }\end{array}$ & $\begin{array}{c}\text { oral antibiotic; } \\
\text { cotrimoxazole }\end{array}$ \\
\hline $\begin{array}{c}\text { Severe pneumonia } \\
\text { pneumonia }\end{array}$ & $\begin{array}{c}\text { lower chest indrawing with or without fast breathing } \\
\text { or difficult to awake, stridor in calm child, or clinically severe } \\
\text { malnutrition. }\end{array}$ & parenteral penicillin \\
& $\begin{array}{c}\text { parenteral } \\
\text { chloramphenicol }\end{array}$ \\
\hline
\end{tabular}

Exclusion criteria was Children with known asthma, those with a history of three or more episodes of wheezing in a year, those in whom lower chest indrawing resolved after three doses of a bronchodilator over 30 minutes, Children who were known to have anaphylactic reactions to penicillin or amoxicillin, having cough for more than 14 days, and those with other infectious diseases that needed antibiotic treatment.

Management strategy: A detailed medical, socioeconomic and immunization history was taken and entered in a predesigned proforma. Clinical examination included anthropometry (weight, length/height, weight for height, mid upper arm circumference, chest circumference, and head circumference), general physical examination and respiratory system examination. Children were randomly divided into two groups. 
Group-I : received intravenous antibiotic (ampicillin) at the dose of $200 \mathrm{mg} / \mathrm{Kg} /$ day divided every 6 hourly.

Group- II : switched to oral amoxycillin at the dose of $40 \mathrm{mg} / \mathrm{Kg} /$ day divided every 8 hourly, after two days of intravenous treatment with ampicillin in the dose same as above.

General supportive care in the hospital, including nebulised salbutamol ( $0.15 \mathrm{mg}$ per $\mathrm{Kg}$ per dose) if wheeze was present, oxygen, and antipyretics were provided when indicated.

Investigations done in all cases included haemoglobin, total leukocyte count, differential count, and chest X-Ray.

Treatment Failure was defined as any of the following; Clinical detrioration; development of danger signs such as inability to drink, abnormal sleepiness, central cyanosis, and convulsions; development of comorbid condition requiring an antibiotic, as diseases like meningitis, dysentry, osteomyelitis, septic arthritis, evident tuberculosis. Persistence of fever $>38$ oC with lower chest indrawing from day 3 to day 6; Inability to take oral medication due to persistent vomiting which was defined as vomiting three repeated doses of oral amoxycillin within 30 minutes of administration; Left against medical advice, death and voluntary withdrawal of consent. Monitoring of child was done by heart rate, respiratory rate, lower chest indrawing, signs of respiratory distress, need for oxygen and auscultation for additional sounds.

\section{Dischargecriteria for patient-}

Group-I: Patients whose clinical status improved to non-severe pneumonia (ie, absence of lower chest indrawing with fast breathing) or better were discharged after completion of seven days of intravenous treatment.

Group-II: Patients whose clinical status improved to non-severe pneumonia (ie, absence of lower chest indrawing with fast breathing) or better were discharged after switching on to oral amoxycillin, with a course of 5 days (total duration).

Children who were classified as treatment failure were treated with a local alternative standard therapy. Patients in Group I were treated by intravenous third generation cephalosporin until improved. Patients in Group II were treated by restarting intravenous ampicillin and if not improved by intravenous third generation cephalosporin until improved.

\section{Results}

Table 1: Treatment Outcome.

\begin{tabular}{|c|c|c|c|c|c|}
\hline S No & Outcome & Group I & Percentage & Group II & Percentage \\
\hline 1 & Death & 00 & $0 \%$ & 00 & $0 \%$ \\
\hline 2 & Improved & 16 & $80 \%$ & 15 & $75 \%$ \\
\hline 3 & Static/Deteriorated & 03 & $15 \%$ & 05 & $25 \%$ \\
\hline 4 & Drop out & 01 & $5 \%$ & 00 & $0 \%$ \\
\hline & Total & $\mathbf{2 0}$ & & $\mathbf{2 0}$ & \\
\hline
\end{tabular}

In the study it was seen that, $80 \%$ of children improved in Group I and $75 \%$ of children improved in Group II, while $15 \%$ of children in Group I were static/deteriorated and $25 \%$ of children were static/deteriorated in Group II. Applying the Chi square test $(0.51)$ the $\mathrm{p}$ value is 0.47 , which shows no statistically significant difference in the treatment outcome of the two groups.

Table 2: Duration of stay in hospital.

\begin{tabular}{|c|c|c|}
\hline S No & Duration of stay & Average duration of stay (days) \\
\hline 1 & Group I & 8.25 \\
\hline 2 & Group II & 5.75 \\
\hline
\end{tabular}

The average duration of stay in hospital was 8.25 days in Group I and 5.75 days in Group II. The p value is 0.04 , which is significant. 
Table 3: Complications/ side effects of therapy.

\begin{tabular}{|c|c|c|c|c|c|}
\hline S No & Complications / side effects & Group-I & \% & Group- II & $\%$ \\
\hline 1 & Oedema/ extravasation at site of cannula & 18 & $90 \%$ & 00 & $0 \%$ \\
\hline 2 & Inflammation at site of cannula & 17 & $85 \%$ & 00 & $0 \%$ \\
\hline 3 & Abscess at site of cannula & 02 & $10 \%$ & 00 & $0 \%$ \\
\hline 4 & Thromboembolism & 00 & $0 \%$ & 00 & $0 \%$ \\
\hline 5 & Switch over to other vein & 20 & $100 \%$ & 00 & $0 \%$ \\
\hline 6 & Vomiting & 00 & $0 \%$ & 00 & $0 \%$ \\
\hline 7 & Diarrhoea & 00 & $0 \%$ & 02 & $10 \%$ \\
\hline
\end{tabular}

In the study, complications such as oedema/ extravasation, inflammation, abscess at site of cannula were seen only in Group I children and not in Group II while diarrhoea occurred in 2 children in Group II, and thromboembolism and vomiting occurred in none.

\section{Discussion}

Treatment Outcome: In the study it was seen that, $80 \%$ of children improved in Group I and $75 \%$ of children improved in Group II, while $15 \%$ of children in Group I were static/deteriorated and $25 \%$ of children were static/deteriorated in Group II. The three children, who were static / deteriorated in Group I, had to be started on other antibiotic i.e. third generation cephalosporin (cefotaxime) and aminoglycoside (amikacin). The children improved after that. Out of the five children who were static/ deteriorated in Group II, the course of intravenous ampicillin had to be prolonged in four children, and they improved after that, while one required change in antibiotic to third generation cephalosporin (cefotaxime) and aminoglycoside (amikacin), and improved after that. Applying the Chi square test (0.51) the p value came out to be 0.47 , which shows no statistically significant difference in the treatment outcome of the two groups.

Study done by APPIS Group (2004) [7] evaluated 1702 patients in their study comparing oral amoxicillin versus intravenous penicillin for two days followed by oral amoxicillin. After 48 hours, treatment failure occurred in 161/845 $(19 \%)$ in the amoxicillin group and 167/857 (19\%) in the parenteral penicillin group. The authors reported similar recovery in both groups at 5 and 14 days.According to study done by Emmanuel Addo Yobo et al (2004) [8] injectable penicillin and oral amoxicillin are equivalent for severe pneumonia treatment in controlled settings. Jeena P( 2004) [8] also supports that injectable penicillin and oral amoxicillin are equivalent in the treatment of severe pneumonia in developing world areas in a controlled environment. An Indian study conducted by Kabra S K (2006 ) [9] also concluded no differences between injectable penicillin and oral amoxicillin.

Duration of stay in hospital: The average duration of stay in hospital was 8.25 days in Group I and 5.75 days in Group II. The $\mathrm{p}$ value came out to be 0.04 , which is significant. Thus there was significant difference in the duration of stay in hospital between the children of two groups.

Following table shows the test results under the ROC curve:

\begin{tabular}{|c|c|c|c|}
\hline $\begin{array}{c}\text { Cut off value } \\
\text { (days) }\end{array}$ & Area under curve & Standard Error & $\begin{array}{c}\text { Test value } \\
\text { (less than } \mathbf{0 . 0 5} \text { is significant) }\end{array}$ \\
\hline 4 & 0.763 & 0.113 & 0.215 \\
\hline $\mathbf{5}$ & $\mathbf{0 . 8 1 3}$ & $\mathbf{0 . 0 7 1}$ & $\mathbf{0 0 1}$ \\
\hline 6 & 0.756 & 0.155 & 0.386 \\
\hline 7 & $\mathbf{0 . 2 4 4}$ & $\mathbf{0 . 0 8 1}$ & $\mathbf{0 . 0 0 9}$ \\
\hline 8 & 0.304 & 0.108 & 0.130 \\
\hline 9 & 0.443 & 0.138 & 0.683 \\
\hline
\end{tabular}




\section{ROC Curve}

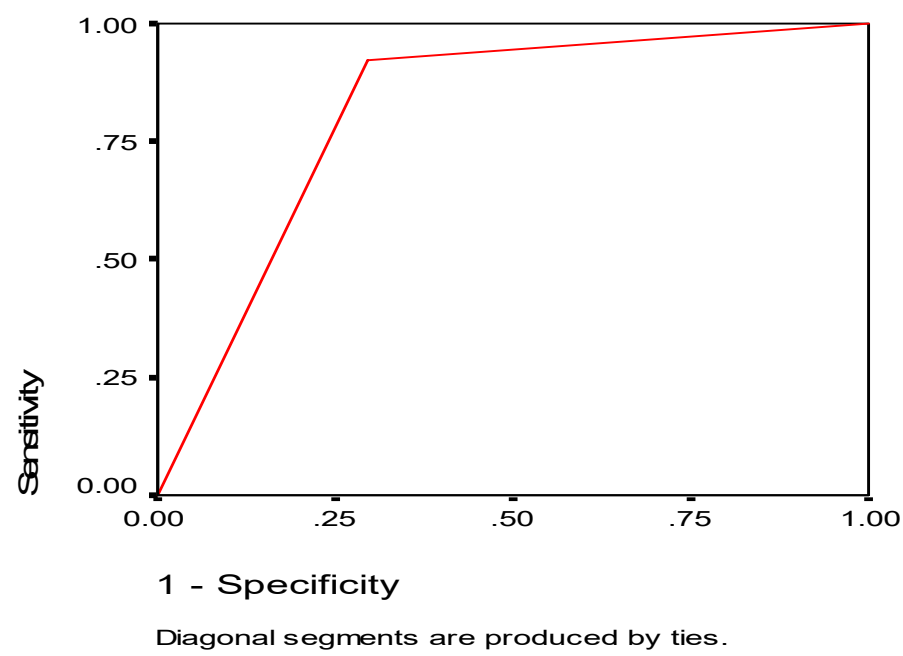

\begin{tabular}{|c|c|}
\hline Duration & Valid N (listwise) \\
\hline Positive(a) & 13 \\
\hline Negative & 27 \\
\hline
\end{tabular}

Larger values of the test result variable (s) indicate stronger evidence for a positive actual state. The positive actual state is 5 .

Area Under the Curve is .813

\section{ROC Curve}

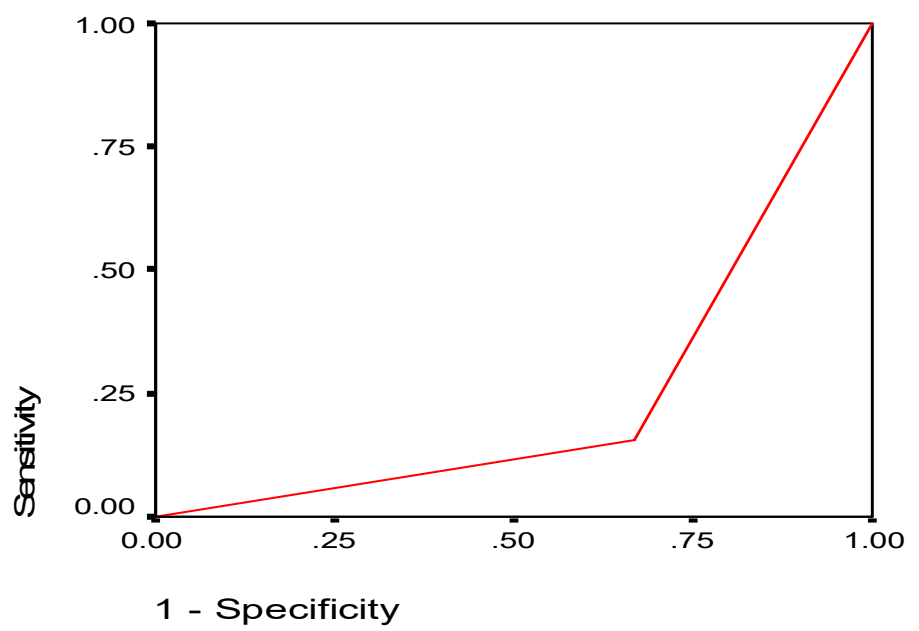

Diagonal segments are produced by ties.

\begin{tabular}{|c|c|}
\hline DURATION & Valid N (listwise) \\
\hline Positive (a) & 13 \\
\hline Negative & 27 \\
\hline
\end{tabular}

Larger values of the test result variable(s) indicate stronger evidence for a positive actual state. The positive actual state is 7 .

Area Under the Curve is . 244 
Ashima Rani et al (2008) [10] conducted a study at Vellore to determine health care provider cost and household cost of the treatment of severe pneumonia in infants and young children admitted to secondary and tertiary level health care facilities. Total cost to health care provider for one episode of hospitalized childhood pneumonia treated at secondary level was US\$ 83.89 (INR 3524) and US\$ 146.59 (INR 6158) at tertiary level. At both levels the greatest single cost was the hospital stay itself, comprising $74 \%$ and $56 \%$ of the total cost, respectively. The authors concluded that a considerable cost difference exists between secondary and tertiary level treatment. Admission at lowest possible treatment level for appropriate patients could decrease the costs borne by the provider and the patient.

Complications/ side effects of therapy: In the study complications such as oedema/ extravasation, inflammation, abscess at site of cannula were seen only in Group I children and not in Group II while diarrhoea occurred in 2 children in Group II, and thromboembolism and vomiting occurred in none.

Admission required for administration of injectable treatment has several drawbacks. First, routine use of injectable antibiotics, either intravenously or intramuscularly, is associated with an increase in the risk of clinically significant morbidity, such as complications of abscess formation at the injection site and transmission of HIV, hepatitis, or other pathogens associated with use of contaminated needles. Second, injection needles and administration equipment are in short supply or periodically unavailable in some settings, preventing delivery of recommended treatment [8].

\section{Conclusion}

Early switch on from intravenous to oral antibiotic therapy in severe pneumonia in children is as effective as treating it with intravenous antibiotics for seven days. The response to therapy, as evaluated by subsidence of fever and improvement in signs of respiratory distress and treatment outcome was similar in the two groups. When patients are first admitted to hospital antibiotics are usually given intravenously to provide optimal concentrations in tissue. The duration of intravenous treatment is an important determinant of length of hospital stay. Conventionally, intravenous treatment is continued until definite clinical cure. A switch to treatment with oral antibiotics will allow early discharge and reduce drug costs. Significantly reduced duration of stay in hospital was seen in the group where switch on to oral antibiotic was made. Also, admission required for administration of injectable treatment has several drawbacks. First, routine use of injectable antibiotics, either intravenously or intramuscularly, is associated with an increase in the risk of clinically significant morbidity, such as complications of abscess formation at the injection site and transmission of HIV, hepatitis, or other pathogens associated with use of contaminated needles. Second, injection needles and administration equipment are in short supply or periodically unavailable in some settings, preventing delivery of recommended treatment. Third, admission can substantially raise the cost of health care.

Present study also supports this hypothesis with; Similar rate of improvement in the signs of respiratory distress and subsidence of fever in the two groups.

- Statistically no significant difference in the treatment outcome of the two groups.

- Significantly reduced duration of stay in hospital of children in whom intervention with switch on to oral antibiotics was done.

- Reduced rate of complications such as oedema/ extravasation, inflammation, abscess at site of cannula in the children in whom switch on to oral antibiotics was made.

\section{Funding: Nil, Conflict of interest: Nil} Permission from IRB: Yes

\section{References}

1. IGME 2015. Levels \& Trends in Child Mortality. Report 2015 Estimates Developed by the UN Interagency Group for Child Mortality Estimation. Available from:http://www.childmortality.org/files_v20/download / IGME\%20 Report\%202015_9_3\%20LR\%20Web.pdf. Accessed May 13, 2016.

2. You D, Hug L, Ejdemyr S, Idele P, Hogan D, Mathers C, et al; United Nations Inter-agency Group for Child Mortality Estimation (UNIGME). Global, regional, and national levels and trends in under-5 mortality between 1990 and 2015, with scenario-based projections to 2030: A systematic analysis by the UN Inter-agency Group for Child Mortality Estimation. Lancet. 2015;386:2275-86.

3. Liu L, Oza S, Hogan D, Perin J, Rudan I, Lawn JE, Et al. Global, regional and national causes of child mortality in 2000-13, with projections to inform post2015 priorities:An updated systematic analysis. Lancet. 2015;385:430-40. 
4. WHO, UNICEF. Integrated Global Action Plan for the Prevention and Control of Pneumonia and Diarrhoea. Geneva: World Health Organization / New York: United Nations Children's Fund, 2013.

5. Yaron Shoham ,Ron Dagan, Noga Givon-Lavi.Et al. Community-Acquired Pneumonia in Children: Quantifying the Burden on Patients and Their Families Including Decrease in Quality of Life. Pediatrics. 2005; 115(5):1213-1219.

6. Integrated Management of Childhood Illness: A WHO / UNICEF initiative. Bull World Health Organization.1997;75: (suppl. 1).

7. Patel AB, Bang A, Singh M, Dhande L, Chelliah LR, Malik A, Et al. A randomized controlled trial of hospital versus home based therapy with oral amoxicillin for severe pneumonia in children aged 3 -
59 months. BMC Pediatr. 2015 Nov 17;15:186. doi: 10. 1186/s12887-015-0510-9.

8. Addo-Yobo E, Chisaka N, Hassan M, Hibberd P, Lozano JM, Jeena $\mathrm{P}$, et al. Oral amoxicillin versus injectable penicillin for severe pneumonia in children aged 3 to 59 months: a randomised multicentre equivalency study. Lancet. 2004;364:1141-8.

9. Kabra SK, Lodha R, Pandey RM. Antibiotics for community-acquired pneumonia in children. Cochrane Database Syst Rev. 2010;3:CD004874.

10. Ashima Rani, Madsen, Helle Ostergaard, Hanehøj, Malin, Das, Et al. Costing of severe pneumonia in hospitalized infants and children aged 2-36 months, at a secondary and tertiary level hospital of a not-for-profit organization. Tropical Medicine \& International Health. 2009;14(10): 1315-22.

\section{How to cite this article?}

Sharma D, Gaur A. Effectiveness of early switch from intravenous to oral antibiotics in severe pneumonia. Int J Pediatr Res.2016;3(6):455-461.doi:10.17511/ijpr.2016.i06.14. 